Review

\title{
Advances in Radiation Oncology for the Treatment of Cervical Cancer
}

\author{
Mame Daro Faye (D) and Joanne Alfieri *(1)
}

Citation: Faye, M.D.; Alfieri, J. Advances in Radiation Oncology for the Treatment of Cervical Cancer. Curr. Oncol. 2022, 29, 928-944. https://doi.org/10.3390/curroncol 29020079

Received: 10 January 2022

Accepted: 4 February 2022

Published: 9 February 2022

Publisher's Note: MDPI stays neutral with regard to jurisdictional claims in published maps and institutional affiliations.

Copyright: (C) 2022 by the authors. Licensee MDPI, Basel, Switzerland. This article is an open access article distributed under the terms and conditions of the Creative Commons Attribution (CC BY) license (https:// creativecommons.org/licenses/by/ $4.0 /)$.

\author{
Division of Radiation Oncology, McGill University Health Centre, Montreal, QC H4A 3J1, Canada; \\ mame.faye@mail.mcgill.ca \\ * Correspondence: joanne.alfieri@mcgill.ca
}

\begin{abstract}
Background: Over the past two decades, there has been significant advancement in the management of cervical cancer, particularly in the domain of definitive chemoradiotherapy for locally advanced cervical cancer (LACC). Indeed, radiation treatment paradigms have shifted from a two-dimensional (2D) approach solely based on anatomical bony landmarks, to an image-guided three-dimensional (3D) approach, with the goal of delivering doses more precisely to clinical targets with an increased sparing of organs-at-risk. Methods: This is a narrative review on the advances in radiation technologies for the treatment of cervical cancer. Using the PubMed database, we identified articles published in English up until November 18, 2021 on the treatment of LACC with external beam radiotherapy (EBRT) and brachytherapy. A search of the Clinicaltrials.gov and Clinicaltrialsregister.eu retrieved information on ongoing clinical trials on the topic of combined immunotherapy and radiotherapy in cervical cancer. Results: We highlight the historical evolution from the use of $2 \mathrm{D}$ radiotherapy to 3D-conformal radiotherapy, and then intensity modulated radiotherapy (IMRT) for the delivery of EBRT. We also discuss advances in brachytherapy, notably the transition to 3D image-guided adaptive brachytherapy (3D-IGABT). In this context, we highlight large cohort studies that were recently constructed and have shown significant improvement in local control and treatment-related toxicities with 3D-IGABT. Finally, we discuss other advances in the field, notably the use of stereotactic body radiotherapy (SBRT) as a substitute to brachytherapy, and the addition of immunotherapy to chemoradiation. Conclusions: The use of IG-IMRT and 3D-IGABT have considerably improved treatment outcomes and toxicity profiles for patients with LACC, and are now considered the gold standard in many countries. The use of SBRT boost as a replacement for brachytherapy has been associated with increased toxicity and decreased efficacy and should be used with caution in the context of clinical trials. New experimental approaches include the addition of immunotherapy to chemoradiation regimens.
\end{abstract}

Keywords: cervical cancer; radiation oncology; radiotherapy; chemoradiation; IMRT; brachytherapy; 3D-IGABT; SBRT; immunotherapy; immune checkpoint inhibitors

\section{Introduction}

Cervical cancer is the fourth most common cancer in women worldwide [1,2]. The majority of cervical cancers in developed countries are diagnosed early at stage I and 5 -year overall survival (OS) for all stages remains above 73\% [3,4]. However, outcomes for those with locally advanced cervical cancer remain quite poor. The 5 -year OS for patients with regional disease is around $55 \%[3,5]$. The addition of concurrent chemotherapy to radiotherapy (RT) has improved the prognosis of these patients; however treatment-related toxicity and distant recurrence remain a challenge [6]. Thus, there is much room for improvement in the treatment of locally advanced cervical cancer and new strategies are needed to further improve outcomes.

Standard treatment of locally advanced cervical cancer (LACC) consists of concurrent chemoradiotherapy (CCRT) with external beam radiotherapy (EBRT), followed by 
brachytherapy (BT) [7]. CCRT has been the standard of care for LACC since 1999, based on the results of five Phase III randomized controlled trials (RCT) showing a 30\% to 50\% survival advantage by adding cisplatin-based chemotherapy to radiation (GOG 85, GOG 120, GOG 123, SWOG 8797/Intergroup 0107, RTOG 9001) [8-12]. In the past two decades, radiation treatment paradigms have shifted from a two-dimensional (2D) approach, solely based on anatomical bony landmarks, to an image-guided three-dimensional (3D) approach, taking into account variations in tumour size and position, with the goal of delivering doses more precisely to clinical targets with an increased sparing of organs-at-risk (OARs).

In this narrative review, we discuss the advances in external beam radiotherapy (EBRT) and brachytherapy (BT) for the treatment of locally advanced cervical cancer. We highlight the historical evolution from the use of 2D radiotherapy to 3D-conformal radiotherapy (3DCRT), and then to intensity modulated radiotherapy (IMRT) that has now become a standard for the planning and delivery of EBRT. We also discuss advances in brachytherapy, notably the evolution from a Manchester system delivery of BT, to now widespread use of 3D image-guided adaptive brachytherapy (3D-IGABT). In this context, we highlight recently conducted large cohort studies that have shown significant improvement in local control (LC) and treatment-related toxicities with 3D-IGABT. Finally, we highlight other technological advances in the field, notably the use of stereotactic body radiotherapy (SBRT) as a potential substitute when brachytherapy is contraindicated, and future directions such as the addition of immunotherapy to chemoradiation.

\section{Material and Methods}

A literature search was performed in the PubMed database for articles on radiotherapy for the treatment of LACC. The following keywords were used in various search algorithms: "cervical cancer", "radiotherapy," "radiation therapy," "chemoradiation", "IMRT", "brachytherapy", "SBRT", "immunotherapy," and "immune checkpoint inhibitors". Original research, review papers, or meeting abstracts published on the topic up to 18 November 2021 were considered. Articles published in languages other than English were excluded. Further references found within the articles and relevant to the subject were also used. A search query was also performed in Clinicaltrials.gov and Clinicaltrialsregister.eu to retrieve information on ongoing clinical trials on combined immunotherapy and RT in cervical cancer.

\subsection{Advances in External Beam Radiotherapy}

\subsubsection{From 2D Radiotherapy to 3D-Conformal Radiotherapy (3DCRT)}

Historically, the treatment of LACC with RT has been performed with 2D external beam radiotherapy, solely based on empirically defined anatomical landmarks. These anatomical bony landmarks were defined based on X-rays to be able to largely cover the primary disease as well as any potential extent of the tumour to the adjacent soft tissues and draining lymph nodes. The most rudimentary technique of EBRT consists of two parallel opposed fields (AP-PA). This was followed by the use of Biaxial Telecobalt pendular irradiation of the pelvic lymph nodes combined with ${ }^{226}$ Radium-BT to treat cervical cancer in the 1960s, especially in the recurrent setting [13]. Later, the "four-field box" technique was introduced and achieved better OARs sparing. It consists of four large treatment fields, with the anterior border placed anteriorly to the pubic symphysis, posterior border covering the sacrum at the S3/S4 level, superior border at the level of the aortic bifurcation around the L3-L5 vertebral body levels, or at the level of T12 in the case of extended fields, when the para-aortic lymph nodes are involved. The inferior border is defined as the bottom of the obturator foramen and finally the lateral borders are placed 1.5 to $2 \mathrm{~cm}$ lateral to the pelvic brim. Although easily applicable, the use of standardized fields based only on bony landmarks has the caveat of not being adaptable to variations in individual patients' anatomy and has been associated with geographical misses leading to decreased LC [14,15]. 
The computerized tomography (CT) scanner was invented in 1971 by Hounsfield and Cormack, but it was not until the 1990s that it was used in the planning and delivery of RT [16], marking the evolution from 2D-RT to 3DCRT. Indeed, 3DCRT takes advantage of the soft tissue and anatomical information obtained from a CT scan of the patient in a reproducible treatment position, to delineate the target disease and the neighboring OARs. Based on this information, gross tumour volume (GTV), clinical target volume (CTV) and planning target volume (PTV) are delineated as defined by the ICRU 50 and 62 reports $[17,18]$. This allowed for the use of the "four field box" technique based on anatomical rather than empirical bony landmarks, and the use of field blocks or multileaf collimators (MLCs) to better shape the dose distribution to the PTV while limiting the dose delivered to the OARs $[19,20]$. Compared to a 2D technique, 3DCRT also provides the advantage of recording volumetric dosimetry, correlating it with treatment outcomes and toxicities.

2.1.2. Intensity Modulated Radiotherapy (IMRT) for the Treatment of Locally Advanced Cervical Cancer

IMRT is a radiotherapy technique that allows for the delivery of highly conformal dose distribution compared to conventional techniques of 2D or 3DCRT, while minimizing the dose to nearby OARs. It achieves this through the use of multiple static beamlets or of volumetric intensity-modulated arcs (VMAT) and inverse planning software that can optimize the dose distribution, based on set constraints and target priorities. The trade-off is an increased volume of normal tissues receiving low doses of radiation. The success of IMRT at achieving such highly conformal dose distributions relies on the accuracy of target volume delineation and the quality of the imaging used. Thus, simulation CT scans are often fused with available diagnostic CT, MRI and PET/CT imaging to aid accurate target and OAR delineation. When available, MRI and/or PET/CT simulation is also favored to capture the anatomy in the treatment position. IMRT also allows for dose escalation to grossly involved pelvic and para-aortic lymph nodes by sequential or simultaneous integrated boost techniques when the planning CT is fused with diagnostic images such as a PET scan [21]. Multiple consensus contouring guidelines exist to help in the delineation of targets and OARs for cervical cancer [22,23] and have been extensively reviewed elsewhere [24].

Initial reports of the use of IMRT for the treatment of gynecological cancers were published in the early 2000s. In 2001, Portelance et al. showed that normal tissue sparing is superior with IMRT in a cohort of 10 patients with cervical cancer planned with IMRT vs. conventional techniques [25]. They showed that the volumes of bladder, rectum and small bowel receiving the prescribed dose of $45 \mathrm{~Gy}$ or higher was significantly decreased when using IMRT compared to conventional RT [25]. In 2002, Mundt et al. [26] reported their experience with intensity-modulated whole pelvic radiotherapy (IM-WPRT) in 40 women with gynecologic malignancies. They showed adequate coverage of the target volumes compared to conventional RT, with $98.1 \%$ of the PTV receiving the prescription dose. There was also an improved toxicity profile, with a decrease in grade 2 acute gastrointestinal toxicity in the IMRT group compared to the conventional whole pelvis RT group (60 vs. $91 \%, p=0.002$ ), and no patient developing grade 3 toxicity [26]. Since then, several other studies have shown a decrease in acute toxicities, notably of gastrointestinal (GI), genitourinary (GU) and hematological toxicities when using IMRT in the treatment of LACC compared to 2D or 3DCRT, without compromising tumour control [27-31]. Notably, a meta-analysis by Lin et al. [32] on the outcomes of IMRT use for the definitive treatment of cervical cancer included a total of 1008 patients (IMRT $=350,3 \mathrm{DCRT} / 2 \mathrm{D}-\mathrm{RT}=658$ ) and showed a significant decrease in the incidence of acute GI and GU toxicities in patients treated with IMRT compared to 3DCRT/2D-RT. Odds ratios (OR) were 0.55 (95\% CI: $0.32-0.95, p=0.03$ ) for grade $\geq 3$ acute GI toxicities and 0.31 (95\% CI: $0.14-0.67, p=0.003)$ for acute GU toxicities [32]. Moreover, there were no difference in 3-year PFS and OS 
when comparing the two techniques [32], showing that IMRT confers equivalent efficacy compared to conventional techniques with a lower toxicity profile.

In the post-operative setting, RTOG 0418 was the first multi-institutional phase II study that evaluated the use of IMRT to the pelvis vs. four-field box conventional RT. The study included 83 patients, 43 with endometrial cancer and 40 with cervical cancer. Patients with endometrial cancer received IMRT alone, whereas patients with cervical cancer received IMRT and weekly cisplatin. The RT dose was 50.4 Gy in 28 fractions to the pelvic lymph nodes and vagina. An analysis of hematological toxicities from this cohort showed that patients with cervical cancer treated with IMRT had grades 1,2 and 3 hematological toxicities of $23 \%, 33 \%$ and $25 \%$, respectively and no grade $4-5$ toxicities [33]. Importantly, the volume of bone marrow receiving 40 Gy correlated with acute hematological toxicities, as $75 \%$ of patients with a $\mathrm{V} 40>37 \%$ experienced grade 2 or higher hematological toxicities compared to $40 \%$ of patients with a V40 $\leq 37 \%(p=0.025)$. A median bone marrow dose of $>34.2$ Gy was also significantly associated with higher rates of grade $\geq 2$ hematological toxicities; however, bone marrow is highly radiosensitive and keeping doses lower than $34.2 \mathrm{~Gy}$ is not sufficient to maintain hematopoiesis, as $43 \%$ of patients with a median bone marrow dose $\leq 34.2$ Gy still experienced hematological toxicities [33]. The role of IMRT in the post-operative setting is equally advantageous to reduce acute GI toxicities, because with the uterus and ovaries removed, there is more room for the small bowel to shift downwards and occupy the pelvis, thus being more at risk of toxicity from RT. The TIME-C trial (NRG/RTOG 1203) is a phase III RCT that evaluated patient-reported acute GI toxicity from baseline to the end of RT, for 278 patients with cervical or endometrial cancer, randomized to post-operative RT using IMRT or a four-field box [34]. Secondary endpoints included a change in patient-reported urinary toxicity and quality of life. IMRT was associated with a significantly smaller decline in patient-reported bowel and urinary symptom scores, less frequent or constant diarrhea, and fewer use of anti-diarrhea medications [34].

\subsubsection{Adaptive External Beam Radiotherapy}

The uterus and cervix are highly susceptible to changes in position during RT delivery, mainly due to variations in bladder and rectal filling and tumour regression during RT [35]. The reported mean interfractional cervical motion varies between 2.3 and $16 \mathrm{~mm}$ in the anterior-posterior direction, 2.7 and $8 \mathrm{~mm}$ in the superior-inferior direction and between 0.3 and $10 \mathrm{~mm}$ in the lateral direction [36]. Thus, the concept of internal target volume (ITV) has been introduced to account for such variations in position [37]. The ITV is generated by doing simulation CT scans on a full and empty bladder and combining the CTV drawn on each of these scans to account for every position change between these two bladder-filling extremes. A PTV margin of 5-7 mm is then added to this ITV to account for setup and position in errors. However, cone beam CT (CBCT) is recommended so as to ensure adequate coverage of the CTV and PTV daily prior to RT delivery. Moreover, this approach has the benefit of decreasing the volume of OARs exposed to higher doses of RT and the use of image-guided IMRT has been associated with a decrease in GI and hematological toxicities compared with IMRT alone [38]. Other adaptive RT technologies have emerged over the past few years to further improve image guidance during EBRT delivery, notably the "plan of the day" approach or the "online adaptive RT" that include same day replanning and are the subject of a recently published review article [39].

\subsection{Advances in Brachytherapy for the Treatment of Locally Advanced Cervical Cancer}

Brachytherapy (BT) is a type of RT in which small, sealed radioactive sources are placed in or near a tumour volume to deliver a therapeutic dose. It is an integral part of the treatment algorithm for LACC as it helps in boosting the RT dose to the local disease to a curative level. The addition of BT to the treatment of LACC is independently associated with a significantly higher survival rate, with up to a $12 \%$ absolute improvement in 4-year OS (from $46 \%$ to $58 \%, p<0.001$ ) with hazard ratios (HR) of 0.66 (95\% CI, $0.60-0.74$ ) [5]. In this SEER database analysis, BT was also associated with significantly improved cancer- 
specific survival (CSS) with a 4-year CSS of $64.3 \%$ vs. $51.5 \%$ for those who did not receive BT $(p<0.001)$ and HR of $0.64(95 \%$ CI, $0.57-0.71)$.

2.2.1. From 2D-Brachytherapy (2D-BT) to 3D Image Guided Adaptive Brachytherapy (3D-IGABT)

Historically, BT for LACC was delivered through a 2D technique, whereby a 2 Gy equivalent cumulative dose (EQD2) of 80 to 85 Gy was delivered according to the Manchester system, to point A defined on X-ray. First introduced in 1938, the Manchester system defined point $A$ as a point $2 \mathrm{~cm}$ superior to the external $O S$ and $2 \mathrm{~cm}$ lateral and perpendicular to the applicator tandem, anatomically representing where the uterine vessels cross the ureter $[40,41]$. Thus, 2D-BT delivers a known dose to point A bilaterally, generating a pear-shaped distribution, but without factoring in patient-specific factors such as tumour size, anatomy, or doses to OARs, as these cannot be readily identified on an X-ray. However, with the advent of $\mathrm{CT}$ and MRI imaging during the procedure, the delivery of BT has evolved to a volume-based approach, taking into account variations in tumour size and position over the treatment course. This allows for conformal treatment of a high-risk clinical target volume (HR-CTV) while simultaneously sparing OARs.

In 2005, the Groupe Européen de Curiethérapie and the European Society for Radiotherapy \& Oncology (GEC-ESTRO) published the first recommendations on the basic concepts of terms utilized for a 3D image-based BT approach [42]. Since then, several consensus contouring guidelines and protocols have been developed for target delineation in cervical cancer brachytherapy [43-45]. Briefly, 3D-BT can be either CT-guided or MRIguided, with the latter being considered the gold standard, as it is required for visualizing and contouring the residual GTV after EBRT. For instance, the EMBRACE-II protocol [46] defines the residual GTV (GTV-Tres) as the residual macroscopic tumour at the time of the BT boost, after treatment that is assumed sufficient to control microscopic disease, and based on clinical examination and imaging (MRI, PET/CT). The adaptive High Risk CTV-T (CTV-T HRadapt) includes the GTV-Tres, the whole cervix and adjacent residual pathologic tissue as defined by clinical examination and imaging at the time of BT (Figure 1). It is the volume bearing the highest risk for recurrence and should receive at least $90 \mathrm{~Gy}$ of cumulative EQD2 as per the EMBRACE-II dose targets (D90 CTV-T HR > 90-95 Gy EQD2 ${ }_{10}$ ). The Intermediate Risk CTV-T (CTV-T IR) represents the area of the GTVinit superimposed on the topography at the time of brachytherapy and a margin surrounding the anatomical cervical borders in areas without an initial GTV-T. Dose distribution and optimization is achieved using different types of applicators that are MRI compatible. Intracavitary applicators can be used for smaller tumours $(<31 \mathrm{cc})$ but are limited at covering the CTV-T HRadapt to doses $>85 \mathrm{~Gy}$, in case of larger tumours or asymmetrical local tumour extension for example to the parametria, vagina, bladder or rectal wall [47,48]. For such cases, a combined intracavitary-interstitial (IC/IS) approach is favoured and allows for improved conformality and target-dose escalation without increasing the doses received by the OARs [47-50]. 


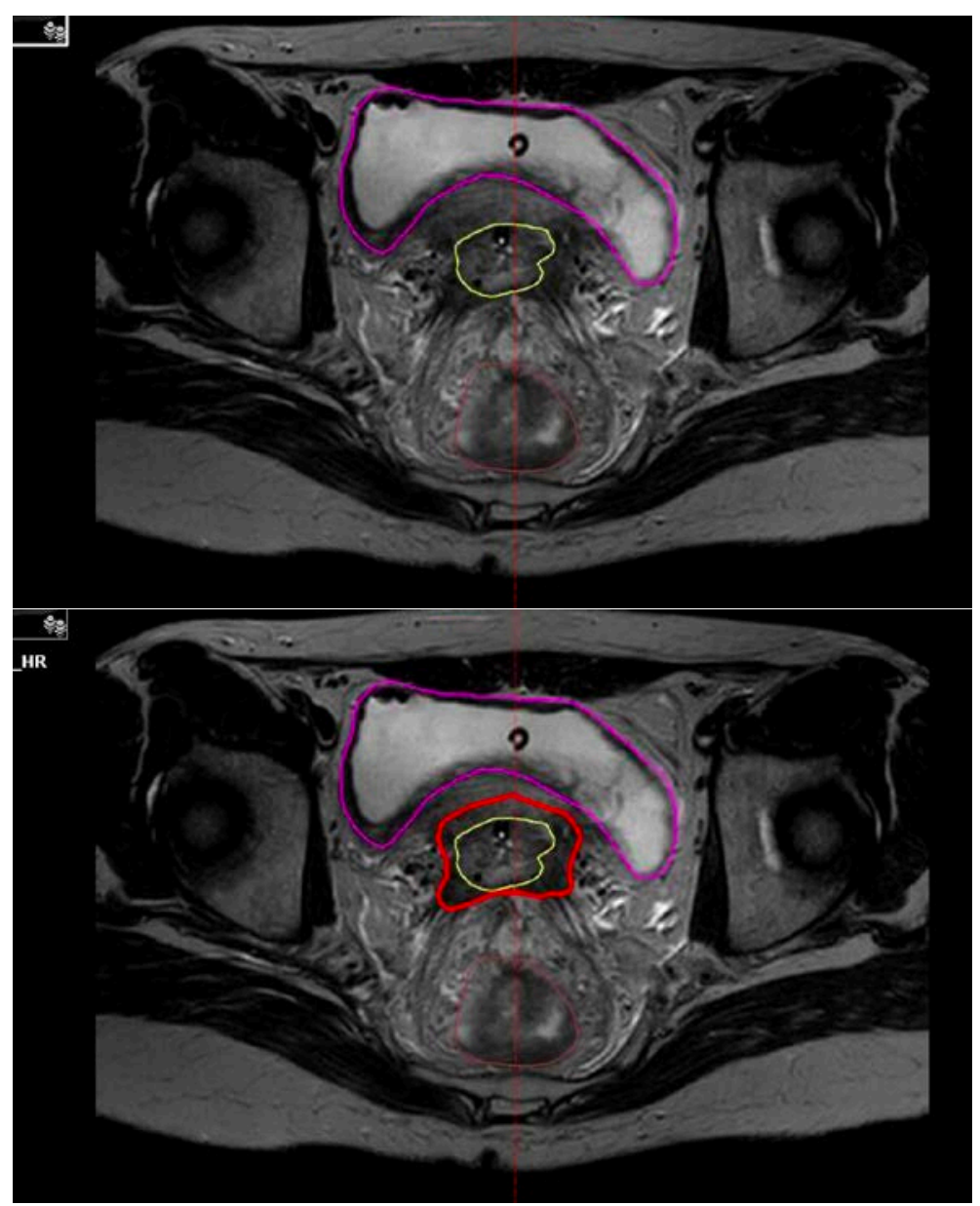

Figure 1. Residual gross tumour volume at brachytherapy (GTV-Tres: yellow) and adaptive High Risk CTV-T (CTV-T HRadapt: red) contoured at the time of brachytherapy on axial T2 MRI.

\subsubsection{Outcomes of 3D Image-Guided Brachytherapy (3D-IGABT)}

Several studies have reported improved LC and survival outcomes, and decreased toxicities with the use of 3D-IGABT compared to 2D-BT. Initiated in 2005, the French STIC trial was the first prospective, non-randomized trial to compare 2D- vs. 3D-BT in the treatment of LACC [51]. A total of 705 LACC patients were treated as per Group 1: BT (2D or 3D) followed by surgery; Group 2: chemoradiation, BT (2D or 3D) followed by surgery, or Group 3: chemoradiation then BT (2D or 3D), for which the 3D-BT was mostly CT-guided. At 24 months, improved LC was observed in all three groups, as well as a $50 \%$ reduction in grade 3 and 4 morbidity with 3D-BT compared to 2D-BT [51]. The RetroEMBRACE study is the largest retrospective, multi-institutional study of its kind reporting on the outcomes of 731 women with LACC, treated with CCRT and 3D-IGABT (either by CT or MRI) [52]. With a median follow-up of 43 months, Sturdza et al. reported excellent 5-year LC rates of $89 \%$, pelvic control (PC) of $84 \%$, cancer-specific survival (CSS) of $73 \%$ and OS of $65 \%$, which is an improvement of $~ 10 \%$ compared to historic controls using 2D-BT. They also reported limited morbidity with grade $\geq 3$ late toxicity rates of $5 \%$, $7 \%$, and $5 \%$, respectively, for the bladder, gastrointestinal tract and vagina [52]. Importantly, for patients treated with MRI-based IGABT, 5-year LC was 94\% for those with tumours $<5 \mathrm{~cm}$ compared to $81 \%$ for tumours $\geq 5 \mathrm{~cm}(p \leq 0.001)$, thus showing how tumour size impacts on LC. The recently published EMBRACE-I prospective, multicentre cohort study evaluated local tumour control and morbidity after chemoradiotherapy and MRI-based IGABT in LACC. They reported an actuarial 5-year LC of $92.0 \%(95 \%$ CI, 90-93) at a median follow-up of 51 months, 5-year PC of $87.0 \%$ (95\% CI, 85-89) and 5-year nodal control of $87.0 \%$ (95\% CI, 85-89). The 5-year disease-free survival (DFS) in this cohort was $68 \%$ (95\%, 
CI 65-70) and 5-year OS was 74\% (95\%, CI 72-77) [53]. LC was similar across all of the stage groups; however there was a 14-17\% absolute improvement in LC in FIGO stage IIIB disease compared to the RetroEmbrace cohort (92\% LC vs. $75 \%$ in RetroEmbrace) $[52,53]$. This could be due to an increase in the use of MRI planning (100\% vs. 19\%) and interstitial needles ( $43 \%$ vs. $23 \%$ ) in EMBRACE-I compared to RetroEmbrace. The initially reported late grade $\geq 3$ bowel and bladder toxicity from the EMBRACE-I cohort were $5.9 \%$ and $5.3 \%$, respectively, $[54,55]$ but the most recent report showed an actuarial cumulative 5-year incidence of grade $\geq 3$ GI toxicity of $8.5 \%(6.9-10.6)$, grade $\geq 3$ GU toxicity of $6.8 \%$ (95\% CI $5.4-8.6), 5.7 \%(4.3-7.6)$ vaginal toxicity and $3.2 \%(2.2-4.5)$ fistula events [53].

Taken together, these studies show the superior safety profile and efficacy, at least in terms of LC, of 3D-IGABT compared to 2D-BT techniques. This has been corroborated by a recent systematic review and meta-analysis by Kim et al. that reported a pooled hazard ratio (HR) for grade $\geq 3$ toxicities of 0.54 for 3D-IGABT compared to $2 \mathrm{D}-\mathrm{BT}$ ( $95 \% \mathrm{CI}$ 0.37-0.77) [56]. There was also a significant improvement in locoregional recurrence-free survival (HR $=0.61 ; 95 \% \mathrm{CI}, 0.40-0.93)$ and $\mathrm{PFS}(\mathrm{HR}=0.75 ; 95 \% \mathrm{CI}, 0.59-0.96)$ favoring 3D-IGABT, but not in OS (HR $=0.65 ; 95 \%$ CI 0.40-1.06). Though MRI-guided IGABT is now considered the gold standard for brachytherapy boost in the treatment of LACC in most European and North American centres, the lack of clear OS benefit in this meta-analysis raises questions as to its widespread adoption, specifically in developing countries where access to MRI planning may be limited. However, the lack of clear OS benefit in this meta-analysis may be because $40 \%$ of patients in the pooled analysis were treated with CT-guided BT and only a few patients received interstitial BT, which could have negatively impacted OS rates. Moreover, a cost-effectiveness analysis performed in the US showed that 3D-IGABT is a cost-effective option compared 2D-BT, thus supporting its routine use in the treatment of LACC [57].

\subsection{Stereotactic Body Radiotherapy in the Treatment of Locally Advanced Cervical Cancer}

Stereotactic body radiotherapy (SBRT) is a type of EBRT whereby high doses of radiation per fraction (usually $>5 \mathrm{~Gy} /$ fraction) are precisely delivered to a target in one or a few fractions. In recent years, SBRT has been considered as a conformal RT boost alternative to BT, particularly in patients unable to undergo BT due to unfavorable anatomy or medical comorbidities. A National Cancer Database registry analysis showed that from 2004 to 2011, the use of BT in LACC decreased from $96.7 \%$ to $86.1 \%$, whereas the use of IMRT and SBRT as a radiation boost increased from $3.3 \%$ to $13.9 \%$ in the same period $(p<0.01)$. However, IMRT or SBRT boost were associated with inferior OS (HR $=1.86 ; 95 \%$ $\mathrm{CI}, 1.35-2.55 ; p<0.01)$, and this decrease was even more significant than that observed when excluding chemotherapy ( $\mathrm{HR}=1.61,95 \% \mathrm{CI}, 1.27-2.04, p<0.01)$ [58]. Another National Cancer Database study later showed no significant difference in OS between the SBRT boost and brachytherapy boost after propensity score matching ( $\mathrm{HR}=1.477,95 \% \mathrm{CI} 0.746-2.926$, $p=0.263$ ), but there was a significant decrease in OS for patients who received IMRT boost vs. brachytherapy boost $(\mathrm{HR}=1.455,95 \%$ CI 1.300-1.628, $p<0.001)$ [59]. However, a recent single-arm phase II trial of SBRT boost (28 Gy in 4 fractions) as an alternative for intracavitary/interstitial BT boost for LACC was closed prematurely after 15 patients were enrolled, owing to concerns of toxicity [60]. Indeed, 2-year cumulative grade $\geq 3$ toxicity was $26.7 \%$, with predominantly rectal ulcers / fistulas. Two of the grade 3 patients died of complications from fistulas, resulting in a grade 5 toxicity rate of $13 \%$ [60]. Moreover, the efficacy of SBRT was inferior with 2-year LC, PFS, and OS of 70.1\%, 46.7\%, and $53.3 \%$, respectively, although the authors argue that larger tumour size and patient comorbidities may have contributed to these inferior outcomes [60]. Another prospective study of SBRT boost for 25 gynecological patients with pelvic relapse or primary disease, of which seven were cervical cancer patients treated with definitive radiotherapy, reported a 1-year in-field RFS of $64.5 \%$ and $90.0 \%$ for the salvage and definitive group, respectively, and a 1-year OS of $80.8 \%$ and $49.1 \%$, respectively [61]. One patient developed an entero-vaginal fistula, one developed sigmoid perforation and no patients experienced grade $\geq 3$ genitourinary 
complications [61]. Taken together, it appears that SBRT boost in LACC results in inferior efficacy compared to BT, but more importantly, it can be associated with serious adverse effects. Thus, caution should be taken when considering this technique in LACC patients that cannot undergo brachytherapy and should only be attempted in the context of a clinical trial with special attention to the dose distribution to the bowel. In their dosimetric analysis, Albuquerque et al. showed that the percentage of rectal circumference receiving 15 Gy (PRC15) was associated with development of a grade 3 ulcer or rectovaginal fistula $(p<0.04)$, with PRC15 $>62.7 \%$ being the strongest predictor of toxicity [60].

On the other hand, when SBRT is used for the treatment of oligometastic cervical cancer, it is associated with favorable response rates and LC. A meta-analysis of 17 studies on SBRT for oligometastic gynecological cancers, including 671 patients, $27.1 \%$ of which had cervical cancer, showed response rates ranging from $49 \%$ to $97 \%$ and LC ranging from $71 \%$ to $100 \%$ [62]. Disease progression occurred most commonly outside of the SBRT radiation field. Toxicity rates ranged from $2.6 \%$ to $10 \%$ and the majority of studies ( 9 out of 16 studies, 56\%) did not report any grade $\geq 3$ toxicities [62].

\subsection{Immunotherapy as an Adjunct to Chemoradiation}

Advances in chemoradiation for the treatment of LACC, notably the use of MRIbased IGABT, have translated into improved LC and toxicity profile. However, the OS for patients with advanced disease remains dismal, and this is thought to be mainly driven by distant failures rather than local recurrences. Thus, new systemic treatments are needed to improve OS for patients with LACC. One of such treatment adjuncts is immunotherapy. Indeed, cervical cancers are thought to be highly immunogenic, as a virusdriven type of cancer (HPV), thus amenable to respond to immunotherapy. Cervical cancer ranks amongst the tumours with the most somatic mutations, neoantigen formation and immune cell infiltrates $[63,64]$. Furthermore, a landmark Cancer Genome Atlas study on invasive cervical cancer identified several targetable mutations in this type of cancer, notably amplifications in the immune checkpoint regulators programmed death ligand (PD-L1 and PD-L2 [65]. Finally, several studies have shown that HPV positivity is associated with increased PD-L1 expression [66,67]. Taken together, all these factors argue for the rationale that cervical cancer tumours would respond to checkpoint-inhibitor targeted therapy.

To date, a few studies have investigated the role of targeted anti PD1/PD-L1 therapy in cervical cancer. The Keynote-28 (NCT02054806) was a single-arm, phase IB basket trial of 477 patients from 20 different cohorts with advanced or metastatic PD-L1-expressing solid tumours, including 24 cervical cancer patients. Patients received pembrolizumab every two weeks for up to 24 months. The primary endpoint was overall response rate as per RECIST v1.1 criteria and secondary endpoint was safety. With a median follow-up of 11 months, the objective response rate (ORR) in the cervical cancer cohort was 17\% (95\% CI, $5 \%$ to $37 \%$ ) with four patients achieving a partial response and median duration of response was 5.4 months (4.1 to 7.5 months) [68]. The 6-month PFS was $13 \%$ and 6-month OS was $66.7 \%$. Treatment-related adverse events (AEs) were reported in 18 patients (75\%) with five patients experiencing grade 3 treatment-related AEs. There were no grade 4 treatment-related AEs or deaths [68].

Furthermore, KEYNOTE-158 (NCT02628067) is an ongoing phase II trial including 1595 patients with advanced (unresectable and/or metastatic) solid tumours who have progressed to standard of care therapy and treated with pembrolizumab [69]. This included a total of 98 patients with previously treated advanced cervical cancer, of which 82 patients (83.7\%) had PD-L1-positive tumours. Pembrolizumab monotherapy was administered every 3 weeks for 2 years until progression. The primary endpoint was ORR as per RECIST v1.1 criteria and secondary endpoints included PFS and OS. With a median follow-up of 10.2 months, ORR was $12.2 \%$ (95\% CI, 6.5-20.4), with three complete and nine partial responses. All 12 responses were observed in patients with PD-L1-positive tumours. Median duration of response was not reached (range, $\geq 3.7$ to $\geq 18.6$ months) at time of interim analysis. Median OS was 9.4 months for the entire cohort and 11.0 months for the 
PD-L1-positive patients. Treatment-related AEs occurred in $65.3 \%$ of patients with grade 3 and 4 treatment-related AEs occurring in $12.2 \%$ of patients. The most common AEs were hypothyroidism (10.2\%), decreased appetite (9.2\%), and fatigue (9.2\%) [69]. These two trials showed that pembrolizumab had durable anti-tumour activity in cervical cancer with acceptable toxicity. Based on this, the Food and Drug Administration (FDA) approved, in June 2018, the use of pembrolizumab for the second-line treatment of PD-L1-positive metastatic or recurrent cervical cancer.

Nivolumab was also shown to have efficacy in advanced/metastatic cervical cancer in the second-line setting. In the phase I/II CHECKMATE 358 (NCT02488759), 24 patients with recurrent or metastatic gynecological cancers (19 cervical, 5 vaginal/vulvar) who had received no more than two previous lines of treatment, were treated with nivolumab every two weeks regardless of PD-L1 status [70]. With a median follow-up of 19.2 months, ORRs were $26.3 \%$ (95\% CI, 9.1-51.2) for cervical cancer and $20.0 \%$ (95\% CI, 0.5-71.6) for vaginal/vulvar cancers. The median duration of response (DOR) was not reached (range, 23.3 to $29.5+$ months) at the time of analysis in the five responding patients in the cervical cohort. Median OS was 21.9 months (95\% CI, 15.1-not reached) for cervical cancer patients. Treatment-related AEs were reported in 12/19 patients $(63.2 \%)$ in the cervical cohort and all five patients in the vaginal/vulvar cohort, with $21.1 \%(n=4)$ being of grade 3 and 4 [70].

In June 2021, Merck announced that a Phase 3 double-blind, randomized trial KEYNOTE826 (NCT03635567) met its primary endpoint of OS and PFS for the first-line treatment of patients with persistent, recurrent or metastatic cervical cancer. A total of 548 patients with a PD-L1 combined positive score of 1 or more received in a 1:1 ratio pembrolizumab or placebo every 3 weeks plus platinum-based chemotherapy and, per investigator discretion, bevacizumab. Primary endpoints were PFS and OS. The results of the first interim analysis were just published in the November 2021 edition of the New England Journal of Medicine, and showed a median PFS of 10.4 months in the pembrolizumab group and 8.2 months in the placebo group (HR for disease progression or death of $0.62 ; 95 \%$ CI, $0.50-0.77$; $p<0.001$ ) [71]. The 2 year-OS was $53.0 \%$ in the pembrolizumab group and $41.7 \%$ in the placebo group (HR for death of $0.64 ; 95 \%$ CI, 0.50-0.81; $p<0.001$ ) [71]. Grade 3 to 5 AEs occurred in $81.8 \%$ of patients in the pembrolizumab group and in $75.1 \%$ of patients in the placebo group, with grade 5 events occurring in 14 patients in each group $(4.6 \%$ and $4.5 \%$, respectively) [71].

In the definitive setting, ENGOT-cx11/KEYNOTE-A18 (NCT04221945) is a phase III, randomized trial evaluating the combination of pembrolizumab with concurrent CRT for the treatment of locally advanced cervical cancer [72]. It is still ongoing and aims to recruit 980 patients with high-risk LACC (FIGO 2014 stage IB2-IIB with node-positive disease or stage III-IVA) who have not received prior treatments, randomized 1:1 to receive either 5 cycles of pembrolizumab vs. placebo every 3 weeks plus CRT followed by 15 cycles of pembrolizumab vs. placebo every 6 weeks. The CRT regimen is as per the standard practice, including 5-6 cycles of cisplatin $40 \mathrm{mg} / \mathrm{m}^{2}$ weekly + EBRT followed by brachytherapy (IGABT). Randomization will be stratified based on the EBRT technique (IMRT or VMAT vs. non-IMRT), cancer stage at screening (stage IB2-IIB vs. III-IVA) and planned total RT dose. The primary endpoints are PFS as per RECIST v1.1 and OS. The secondary endpoints are 2-year PFS, 3-year OS, complete response at 12 weeks, ORR, PFS and OS in PD-L1-positive patients, EORTC QLQ-C30 and QLQ-CX24, and safety. Results of this trial are highly anticipated and will further elucidate whether immunotherapy combined with definitive CRT can improve LC, PC and survival in patients with LACC. Currently, there are ten clinical trials assessing the combination of immunotherapy and definitive chemoradiation in the treatment of cervical cancer (Table 1). Results from all these trials are eagerly awaited to assess whether immunotherapy could improve distant control as well as survival rates in LACC without significantly increasing toxicities. 
Table 1. Clinical trials combining immunotherapy with definitive radiotherapy in the treatment of locally advanced cervical cancer.

\begin{tabular}{|c|c|c|c|c|c|c|}
\hline Trial ID & Design & Eligibility & Intervention & Details & Outcome Measures & Status \\
\hline $\begin{array}{l}\text { NCT04221945 } \\
\text { (KEYNOTE- } \\
\text { A18/ENGOT- } \\
\text { cx11/GOG-3047) }\end{array}$ & Randomized Phase III & $\begin{array}{l}\text { FIGO } 2014 \text { Stage IB2-IIB } \\
\text { (with N+ disease) or } \\
\text { FIGO } 2014 \text { Stages } \\
\text { III-IVA cervical cancer }\end{array}$ & $\begin{array}{l}\text { Pembrolizumab + CRT } \\
+ \text { BT vs. Placebo + CRT } \\
+ \text { BT }\end{array}$ & $\begin{array}{l}\text { Pembrolizumab } 200 \mathrm{mg} \\
\text { IV vs. placebo q3 weeks } \\
\times 5 \text { cycles, followed by } \\
\text { Pembrolizumab } 400 \mathrm{mg} \\
\text { IV vs. placebo q6 weeks } \\
\times 15 \text { cycles } \\
+ \text { Cisplatin qweek during } \\
\text { EBRT + BT (to a total RT } \\
\text { dose of } 80 \text { Gy for volume } \\
\text { directed and } 75 \text { Gy for } \\
\text { point directed }\end{array}$ & $\begin{array}{l}\text { Primary: PFS (RECIST 1.1), } \\
\text { OS } \\
\text { Secondary: 2-year PFS, } \\
\text { 3-year OS, CR at } 12 \text { weeks, } \\
\text { ORR, PFS and OS in } \\
\text { PD-L1+ patients, PFS after } \\
\text { next line treatment, } \\
\text { EORTC QLQ-C30, } \\
\text { QLQ-CX24, and safety }\end{array}$ & Recruiting \\
\hline NCT02635360 & Randomized Phase II & $\begin{array}{l}\text { Confirmed cervical } \\
\text { Cancer (excluded: } \\
\text { distant metastases) }\end{array}$ & $\begin{array}{l}\text { Pembrolizumab } \\
\text { following CRT vs. } \\
\text { Pembrolizumab } \\
\text { concurrent with CRT }\end{array}$ & $\begin{array}{l}\text { CRT followed by } \\
\text { Pembrolizumab } 200 \mathrm{mg} \\
\text { IV q21 days } \times 3 \text { months } \\
\text { Vs Pembrolizumab } \\
200 \mathrm{mg} \text { IV q21 days at } \\
\text { the same time as CRT }\end{array}$ & $\begin{array}{l}\text { Primary: Change in } \\
\text { immunologic markers, } \\
\text { Incidence of DLTs } \\
\text { Secondary: Metabolic } \\
\text { Response Rate on PET/CT, } \\
\text { Incidence of distant } \\
\text { metastases, PFS, OS }\end{array}$ & Active, not recruiting \\
\hline
\end{tabular}


Table 1. Cont.

\begin{tabular}{|c|c|c|c|c|c|c|}
\hline Trial ID & Design & Eligibility & Intervention & Details & Outcome Measures & Status \\
\hline $\begin{array}{l}\text { NCT03612791 } \\
\text { (ATEZOLACC) }\end{array}$ & Randomized Phase II & $\begin{array}{l}\text { FIGO } 2009 \text { stage IB1-IIA } \\
(\mathrm{N}+) \text { or stage IIB-IVA } \\
\text { cervical cancer }\end{array}$ & $\begin{array}{l}\text { Atezolizumab + SoC } \\
\text { CRT + BT } \\
\text { vs. SoC CRT + BT }\end{array}$ & $\begin{array}{l}\text { Atezolizumab } 1200 \mathrm{mg} \\
\text { IV q3 week starting on } \\
\text { week1 and continued as } \\
\text { adjuvant treatment for a } \\
\text { max of } 20 \text { cycles + } \\
\text { Cisplatin qweek } \\
\text { concurrent with pelvic } \\
+/- \text { para-aortic EBRT by } \\
\text { IMRT ( } 45 \text { Gy / } 25 \mathrm{Fx})+ \text { BT } \\
\text { starting at week } 7 \text { ( } 85 \text { Gy } \\
\text { EQD2 to HR-CTV) } \\
\text { vs concurrent CRT +BT } \\
\text { alone as above }\end{array}$ & Primary: PFS (RECIST 1.1) & Recruiting \\
\hline $\begin{array}{l}\text { NCT03527264 } \\
\text { (BrUOG 355) }\end{array}$ & $\begin{array}{l}\text { Non-randomized } \\
\text { Phase II }\end{array}$ & Cervical cancer & $\begin{array}{l}\text { Nivolumab induction }+ \\
\text { Nivolumab concurrent } \\
\text { with chemoradiation }+ \\
\text { Nivolumab maintenance }\end{array}$ & $\begin{array}{l}\text { Cohort 1A: Nivolumab } \\
\text { induction ( } 240 \text { mg IV } \times \\
2 \text { doses) + Nivolumab } \\
240 \text { mg IV q14 days for } \\
3 \text { doses concurrent on } \\
\text { day } 1 \text { with Cisplatin } \\
\text { qweek and EBRT } \\
\text { (45 Gy/25 Fx) } \\
\text { Cohort 1B: As above but } \\
\text { with EFRT } \\
\text { Cohort 2: Nivolumab } \\
\text { induction as above + } \\
\text { CRT w/o Nivolumba + } \\
\text { Maintenance Nivolumab } \\
\text { (480 mg IV q4weeks } \times \\
2 \text { years) } \\
\text { Cohort } 3: \text { Nivolumab } \\
\text { induction + Nivolumab } \\
\text { with CRT + Mainte- } \\
\text { nance Nivolumab }\end{array}$ & $\begin{array}{l}\text { Primary: Feasibility of the } \\
\text { incorporation of } \\
\text { nivolumab with weekly } \\
\text { cisplatin and EFRT or } \\
\text { WPRT in women with } \\
\text { cervical cancer (acute } \\
\text { toxicities as per CTCAE } \\
\text { v4.0), PFS }\end{array}$ & Active, not recruiting \\
\hline
\end{tabular}


Table 1. Cont.

\begin{tabular}{|c|c|c|c|c|c|c|}
\hline Trial ID & Design & Eligibility & Intervention & Details & Outcome Measures & Status \\
\hline NCT03298893 (NiCOL) & Single arm Phase I/II & $\begin{array}{l}\text { Stage IB2-IVA } \\
\text { squamous-cell } \\
\text { carcinoma or } \\
\text { adenocarcinoma of } \\
\text { the cervix }\end{array}$ & $\begin{array}{l}\text { Nivolumab + CRT } \\
\text { followed by } 5 \text { months of } \\
\text { Nivolumab alone }\end{array}$ & $\begin{array}{l}\text { Nivolumab IV q2 weeks } \\
+ \text { Cisplastin + EBRT } \\
(45 \mathrm{~Gy} / 25 \mathrm{Fx} \text { by } \\
\text { IMRT/VMAT + / - SIB } \\
\text { to } 54 \mathrm{~Gy} / 25 \mathrm{Fx})\end{array}$ & $\begin{array}{l}\text { Primary: rate of DLT } \\
\text { Secondary: ORR, PFS, } \\
\text { DFS, Incidence of SAEs } \\
\text { and AEs, molecular } \\
\text { alterations, ctDNA } \\
\text { heterogeneity, tumour } \\
\text { microenvironment } \\
\text { description, tumour } \\
\text { PD-L1 IHC }\end{array}$ & Active, not recruiting \\
\hline NCT03830866 (CALLA) & Phase III RCT & $\begin{array}{l}\text { FIGO (2009) Stages IB2 } \\
\text { to IIB N+ or FIGO (2009) } \\
\text { IIIA-IVA any node } \\
\text { cervical adenoCa or SCC }\end{array}$ & $\begin{array}{l}\text { Durvalumab + SoC CRT } \\
+ \text { BT followed by } \\
\text { Durvalumab } \\
\text { monotherapy up to } \\
24 \text { months or until } \\
\text { progression of disease, } \\
\text { vs. Placebo + SoC CRT } \\
+ \text { BT }\end{array}$ & $\begin{array}{l}\text { Durvalumab IV q4 } \\
\text { weeks + Cisplatin (or } \\
\text { Carboplatin) qweek } \\
\text { concurrent with EBRT } \\
+ \text { BT }\end{array}$ & $\begin{array}{l}\text { Primary: PFS (RECIST 1.1) } \\
\text { Secondary: OS, CR } \\
\text { (RECIST 1.1), duration of } \\
\text { response, QoL (EORTC } \\
\text { QLQ-C30, EORTC CX24), } \\
\text { 3-year PFS, PFS and OS in } \\
\text { PD-L1+ patients }\end{array}$ & Active, not recruiting \\
\hline
\end{tabular}


Table 1. Cont.

\begin{tabular}{|c|c|c|c|c|c|c|}
\hline Trial ID & Design & Eligibility & Intervention & Details & Outcome Measures & Status \\
\hline NCT01158248 & Phase II & $\begin{array}{l}\text { Stage IB-IIIB cervical } \\
\text { cancer with no PA LNs }\end{array}$ & $\begin{array}{l}\text { Panitumumab + CRT } \\
+\mathrm{BT}\end{array}$ & $\begin{array}{l}\text { Panitumumab + } \\
\text { CRT+ BT }\end{array}$ & $\begin{array}{l}\text { Primary: PFS at } 4 \text { months } \\
\text { by MRI according to } \\
\text { RECIST, Rate of skin } \\
\text { and/or gastrointestinal } \\
\text { toxicity CTCAE grade } 4 \text { at } \\
4 \text { months } \\
\text { Secondary: ORR at } \\
4 \text { months according to } \\
\text { RECIST criteria, PFS and } \\
\text { OS at } 12 \text { and } 24 \text { months, } \\
\text { rate of SAEs at } 4,12 \text {, } \\
24 \text { months, Rate of SAEs } \\
\text { of panitumumab } \\
\text { monotherapy at day } 14\end{array}$ & Unknown \\
\hline $\begin{array}{l}\text { NCT04580771 } \\
\text { (IMMUNOCERV) }\end{array}$ & Single arm Phase II & $\begin{array}{l}\text { Stage IB3-IVA } \\
\text { cervical cancer }\end{array}$ & $\begin{array}{l}\text { Liposomal HPV-16 } \\
\text { E6/E7 Multipeptide } \\
\text { Vaccine (PDS0101) + } \\
\text { SoC CRT (Cisplatin } \\
+ \text { RT) }\end{array}$ & $\begin{array}{l}\text { RT (Monday-Friday) for } \\
5-7 \text { weeks _Cisplatin IV } \\
\text { qweek during the } \\
5 \text { weeks of RT + PDS0101 } \\
\text { SC on days -10, 7, 28, 49, } \\
\text { and } 170 \text { in the absence of } \\
\text { disease progression or } \\
\text { unacceptable toxicity. }\end{array}$ & $\begin{array}{l}\text { Primary: Rate of grade } \\
\geq 3 \text { acute toxicity } \\
\text { Secondary: complete } \\
\text { metabolic response rate of } \\
\geq 90 \% \text { GTV reduction, LC, } \\
\text { PFS, OS at } 12 \text { and } \\
18 \text { months, Long term } \\
\text { safety (rate of grade } \geq 3 \\
\text { chronic toxicity) }\end{array}$ & Recruiting \\
\hline
\end{tabular}

RT: radiotherapy; EBRT: external beam radiotherapy; IMRT: intensity modulated radiotherapy; BT: brachytherapy; SoC CRT: standard of care chemoradiation consisting of weekly cisplatin concurrent with pelvic + / - para-aortic EBRT (45Gy / 25Fx) followed by BT (to 80-90 Gy EQD2); EFRT: extended field radiotherapy, WPRT: whole pelvic radiation therapy; N+: node positive, LNs: lymph nodes, PA: para-aortic, adenoCa: adenocarcinoma; SCC: squamous cell carcinoma; ORR: objective response rate; PFS: progression-free survival; OS: overall survival; DFS: Disease Free Survival; MTD: maximum tolerated dose; dose-limiting toxicities (DLTs); AEs: adverse events; SAEs: serious adverse events. 


\section{Conclusions and Perspectives}

RT plays a primordial role in the treatment of LACC. Radiation oncology technologies have progressed rapidly in the past two decades. Notably, the use of IG-IMRT and 3DIGABT have considerably improved treatment outcomes and toxicity profiles for patients with LACC and are now considered the gold standard in many countries. However, there is still room for improvement, and new experimental perspectives include the addition of immunotherapy to chemoradiation regimens, or a move towards an even more personalized approach to treatment with the identification of risk factors and biomarkers that can be used to de-escalate or intensify treatments according to individual patients' risk group (EMBRACE III). Other technological innovations such as the use of the SBRT boost to replace BT boost have been associated with increased toxicity and decreased efficacy and so should be used with caution and only in the context of clinical trials.

Author Contributions: Both authors have contributed equally in the conception and design of the work; Writing—original draft preparation, M.D.F. Writing—critical review and editing, J.A. All authors have read and agreed to the published version of the manuscript.

Funding: This research received no external funding.

Conflicts of Interest: The authors declare no conflict of interest.

\section{References}

1. Bray, F.; Ferlay, J.; Soerjomataram, I.; Siegel, R.L.; Torre, L.A.; Jemal, A. Global cancer statistics 2018: GLOBOCAN estimates of incidence and mortality worldwide for 36 cancers in 185 countries. CA Cancer J. Clin. 2018, 68, 394-424. [CrossRef] [PubMed]

2. Brenner, D.R.; Weir, H.K.; Demers, A.A.; Ellison, L.F.; Louzado, C.; Shaw, A.; Turner, D.; Woods, R.R.; Smith, L.M.; Canadian Cancer Statistics Advisory Committee. Projected estimates of cancer in Canada in 2020. CMAJ 2020, 192, E199-E205. [CrossRef] [PubMed]

3. Benard, V.B.; Watson, M.; Saraiya, M.; Harewood, R.; Townsend, J.S.; Stroup, A.M.; Weir, H.K.; Allemani, C. Cervical cancer survival in the United States by race and stage (2001-2009): Findings from the CONCORD-2 study. Cancer 2017, 123 (Suppl. 24), 5119-5137. [CrossRef] [PubMed]

4. Canadian Cancer Society's Advisory Committee on Cancer Statistics. Canadian Cancer Statistics 2017. Available online: http://www.cancer.ca/en/cancer-information/cancer-type/cervical/statistics/?region=on\#ixzz5cntbaO3P (accessed on 8 February 2021).

5. Han, K.; Milosevic, M.; Fyles, A.; Pintilie, M.; Viswanathan, A.N. Trends in the utilization of brachytherapy in cervical cancer in the United States. Int. J. Radiat. Oncol. Biol. Phys. 2013, 87, 111-119. [CrossRef]

6. Chemoradiotherapy for Cervical Cancer Meta-Analysis Collaboration. Reducing uncertainties about the effects of chemoradiotherapy for cervical cancer: A systematic review and meta-analysis of individual patient data from 18 randomized trials. J. Clin. Oncol. 2008, 26, 5802. [CrossRef]

7. National Comprehensive Cancer Network. Cervical Cancer Version 4.2019. Available online: https://www2.tri-kobe.org/nccn/ guideline/gynecological/english/cervical.pdf (accessed on 8 February 2021).

8. Morris, M.; Eifel, P.J.; Lu, J.; Grigsby, P.W.; Levenback, C.; Stevens, R.E.; Rotman, M.; Gershenson, D.M.; Mutch, D.G. Pelvic radiation with concurrent chemotherapy compared with pelvic and para-aortic radiation for high-risk cervical cancer. $N$. Engl. J. Med. 1999, 340, 1137-1143. [CrossRef]

9. Keys, H.M.; Bundy, B.N.; Stehman, F.B.; Muderspach, L.I.; Chafe, W.E.; Suggs, C.L., 3rd; Walker, J.L.; Gersell, D. Cisplatin, radiation, and adjuvant hysterectomy compared with radiation and adjuvant hysterectomy for bulky stage IB cervical carcinoma. N Engl J. Med. 1999, 340, 1154-1161. [CrossRef]

10. Whitney, C.W.; Sause, W.; Bundy, B.N.; Malfetano, J.H.; Hannigan, E.V.; Fowler, W.C., Jr.; Clarke-Pearson, D.L.; Liao, S.Y. Randomized comparison of fluorouracil plus cisplatin versus hydroxyurea as an adjunct to radiation therapy in stage IIB-IVA carcinoma of the cervix with negative para-aortic lymph nodes: A Gynecologic Oncology Group and Southwest Oncology Group study. J. Clin. Oncol. 1999, 17, 1339-1348. [CrossRef]

11. Peters, W.A., 3rd; Liu, P.Y.; Barrett, R.J., 2nd; Stock, R.J.; Monk, B.J.; Berek, J.S.; Souhami, L.; Grigsby, P.; Gordon, W., Jr.; Alberts, D.S. Concurrent chemotherapy and pelvic radiation therapy compared with pelvic radiation therapy alone as adjuvant therapy after radical surgery in high-risk early-stage cancer of the cervix. J. Clin. Oncol. 2000, 18, 1606-1613. [CrossRef]

12. Rose, P.G.; Bundy, B.N.; Watkins, E.B.; Thigpen, J.T.; Deppe, G.; Maiman, M.A.; Clarke-Pearson, D.L.; Insalaco, S. Concurrent cisplatin-based radiotherapy and chemotherapy for locally advanced cervical cancer. N. Engl. J. Med. 1999, 340, 1144-1153. [CrossRef]

13. Husstedt, W.; Oberheuser, F. Results of irradiation in recurrent collum carcinoma. Fortschr. Med. 1977, 95, 355-357. [PubMed] 
14. Kim, R.Y.; McGinnis, L.S.; Spencer, S.A.; Meredith, R.F.; Jennelle, R.L.; Salter, M.M. Conventional four-field pelvic radiotherapy technique without computed tomography-treatment planning in cancer of the cervix: Potential geographic miss and its impact on pelvic control. Int. J. Radiat. Oncol. Biol. Phys. 1995, 31, 109-112. [CrossRef]

15. Bonin, S.R.; Lanciano, R.M.; Corn, B.W.; Hogan, W.M.; Hartz, W.H.; Hanks, G.E. Bony landmarks are not an adequate substitute for lymphangiography in defining pelvic lymph node location for the treatment of cervical cancer with radiotherapy. Int. J. Radiat. Oncol. Biol. Phys. 1996, 34, 167-172. [CrossRef]

16. Ambrose, J.; Hounsfield, G. Computerized transverse axial tomography. Br. J. Radiol. 1973, 46, 148-149. [CrossRef]

17. International Commission on Radiation Units and Measurements. ICRU Report 50 Prescribing, Recording, and Reporting Photon Beam Therapy; International Commission on Radiation Units and Measurements: Bethesda, MD, USA, 1993 ; Volume 21.

18. International Commission on Radiation Units and Measurments. Prescribing, Recording, and Reporting Photon Beam Therapy; ICRU Report. Volume 62; Supplement to ICRU report 50, 1956; International Commission on Radioation Units and Measurements: Bethesda, MD, USA, 1999; Volume 21.

19. Gerstner, N.; Wachter, S.; Knocke, T.H.; Fellner, C.; Wambersie, A.; Pötter, R. The benefit of Beam's eye view based 3D treatment planning for cervical cancer. Radiother. Oncol. 1999, 51,71-78. [CrossRef]

20. Olofsen-van Acht, M.J.; Quint, S.; Seven, M.; van Santvoort, J.P.; van den Berg, H.A.; Logmans, A.; Levendag, P.C. ThreeDimensional Treatment Planning for Postoperative Radiotherapy in Patients with Node-Positive Cervical Cancer Comparison between a Conventional and a Conformal Technique. Strahlenther. Und Onkol. 1999, 175, 462-469. [CrossRef]

21. Vargo, J.A.; Kim, H.; Choi, S.; Sukumvanich, P.; Olawaiye, A.B.; Kelley, J.L.; Edwards, R.P.; Comerci, J.T.; Beriwal, S. Extended field intensity modulated radiation therapy with concomitant boost for lymph node-positive cervical cancer: Analysis of regional control and recurrence patterns in the positron emission tomography/computed tomography era. Int. J. Radiat. Oncol. Biol. Phys. 2014, 90, 1091-1098. [CrossRef]

22. Lim, K.; Small, W., Jr.; Portelance, L.; Creutzberg, C.; Jürgenliemk-Schulz, I.M.; Mundt, A.; Mell, L.K.; Mayr, N.; Viswanathan, A.; Jhingran, A.; et al. Consensus guidelines for delineation of clinical target volume for intensity-modulated pelvic radiotherapy for the definitive treatment of cervix cancer. Int. J. Radiat. Oncol. Biol. Phys. 2011, 79, 348-355. [CrossRef]

23. Small, W., Jr.; Bosch, W.R.; Harkenrider, M.M.; Strauss, J.B.; Abu-Rustum, N.; Albuquerque, K.V.; Beriwal, S.; Creutzberg, C.L.; Eifel, P.J.; Erickson, B.A.; et al. NRG Oncology/RTOG Consensus Guidelines for Delineation of Clinical Target Volume for Intensity Modulated Pelvic Radiation Therapy in Postoperative Treatment of Endometrial and Cervical Cancer: An Update. Int. J. Radiat. Oncol. Biol. Phys. 2021, 109, 413-424. [CrossRef]

24. Williamson, C.; Liu, H.; Mayadev, J.; Mell, L. Advances in external beam radiation therapy and brachytherapy for cervical cancer. Clin. Oncol. 2021, 33, 567-578. [CrossRef]

25. Portelance, L.; Chao, K.S.; Grigsby, P.W.; Bennet, H.; Low, D. Intensity-modulated radiation therapy (IMRT) reduces small bowel, rectum, and bladder doses in patients with cervical cancer receiving pelvic and para-aortic irradiation. Int. J. Radiat. Oncol. Biol. Phys. 2001, 51, 261-266. [CrossRef]

26. Mundt, A.J.; Lujan, A.E.; Rotmensch, J.; Waggoner, S.E.; Yamada, S.D.; Fleming, G.; Roeske, J.C. Intensity-modulated whole pelvic radiotherapy in women with gynecologic malignancies. Int. J. Radiat. Oncol. Biol. Phys. 2002, 52, 1330-1337. [CrossRef]

27. Rose, B.S.; Aydogan, B.; Liang, Y.; Yeginer, M.; Hasselle, M.D.; Dandekar, V.; Bafana, R.; Yashar, C.M.; Mundt, A.J.; Roeske, J.C.; et al. Normal tissue complication probability modeling of acute hematologic toxicity in cervical cancer patients treated with chemoradiotherapy. Int. J. Radiat. Oncol. Biol. Phys. 2011, 79, 800-807. [CrossRef] [PubMed]

28. Simpson, D.R.; Song, W.Y.; Moiseenko, V.; Rose, B.S.; Yashar, C.M.; Mundt, A.J.; Mell, L.K. Normal tissue complication probability analysis of acute gastrointestinal toxicity in cervical cancer patients undergoing intensity modulated radiation therapy and concurrent cisplatin. Int. J. Radiat. Oncol. Biol. Phys. 2012, 83, e81-6. [CrossRef] [PubMed]

29. Huang, J.; Gu, F.; Ji, T.; Zhao, J.; Li, G. Pelvic bone marrow sparing intensity modulated radiotherapy reduces the incidence of the hematologic toxicity of patients with cervical cancer receiving concurrent chemoradiotherapy: A single-center prospective randomized controlled trial. Radiat. Oncol. 2020, 15, 180. [CrossRef]

30. Gandhi, A.K.; Sharma, D.N.; Rath, G.K.; Julka, P.K.; Subramani, V.; Sharma, S.; Manigandan, D.; Laviraj, M.A.; Kumar, S.; Thulkar, S. Early clinical outcomes and toxicity of intensity modulated versus conventional pelvic radiation therapy for locally advanced cervix carcinoma: A prospective randomized study. Int. J. Radiat. Oncol. Biol. Phys. 2013, 87, 542-548. [CrossRef]

31. Gandhi, A.K.; Sharma, D.N.; Rath, G.K.; Julka, P.K.; Subramani, V.; Sharma, S.; Manigandan, D.; Kumar, S. Long Term Clinical Outcome and Late Toxicity of Intensity Modulated Versus Conventional Pelvic Radiation Therapy for Locally Advanced Cervix Carcinoma. J. Clin. Diagn. Res. 2019, 13, XC09-XC13. [CrossRef]

32. Lin, Y.; Chen, K.; Lu, Z.; Zhao, L.; Tao, Y.; Ouyang, Y.; Cao, X. Intensity-modulated radiation therapy for definitive treatment of cervical cancer: A meta-analysis. Radiat. Oncol. 2018, 13, 177. [CrossRef]

33. Klopp, A.H.; Moughan, J.; Portelance, L.; Miller, B.E.; Salehpour, M.R.; Hildebrandt, E.; Nuanjing, J.; D’Souza, D.; Souhami, L.; Small, W., Jr. Hematologic toxicity in RTOG 0418: A phase 2 study of postoperative IMRT for gynecologic cancer. Int. J. Radiat. Oncol. Biol. Phys. 2013, 86, 83-90. [CrossRef]

34. Klopp, A.H.; Yeung, A.R.; Deshmukh, S.; Gil, K.M.; Wenzel, L.; Westin, S.N.; Gifford, K.; Gaffney, D.K.; Small, W., Jr.; Thompson, S. Patient-reported toxicity during pelvic intensity-modulated radiation therapy: NRG Oncology-RTOG 1203. J. Clin. Oncol. 2018, 36, 2538. [CrossRef] 
35. Chan, P.; Dinniwell, R.; Haider, M.A.; Cho, Y.B.; Jaffray, D.; Lockwood, G.; Levin, W.; Manchul, L.; Fyles, A.; Milosevic, M. Interand intrafractional tumor and organ movement in patients with cervical cancer undergoing radiotherapy: A cinematic-MRI point-of-interest study. Int. J. Radiat. Oncol. Biol. Phys. 2008, 70, 1507-1515. [CrossRef] [PubMed]

36. Jadon, R.; Pembroke, C.A.; Hanna, C.L.; Palaniappan, N.; Evans, M.; Cleves, A.E.; Staffurth, J. A systematic review of organ motion and image-guided strategies in external beam radiotherapy for cervical cancer. Clin. Oncol. (R. Coll. Radiol.) 2014, 26, 185-196. [CrossRef] [PubMed]

37. Bondar, L.; Hoogeman, M.; Mens, J.W.; Dhawtal, G.; de Pree, I.; Ahmad, R.; Quint, S.; Heijmen, B. Toward an individualized target motion management for IMRT of cervical cancer based on model-predicted cervix-uterus shape and position. Radiother. Oncol. 2011, 99, 240-245. [CrossRef] [PubMed]

38. Liang, Y.; Bydder, M.; Yashar, C.M.; Rose, B.S.; Cornell, M.; Hoh, C.K.; Lawson, J.D.; Einck, J.; Saenz, C.; Fanta, P.; et al. Prospective study of functional bone marrow-sparing intensity modulated radiation therapy with concurrent chemotherapy for pelvic malignancies. Int. J. Radiat. Oncol. Biol. Phys. 2013, 85, 406-414. [CrossRef]

39. Shelley, C.E.; Barraclough, L.H.; Nelder, C.L.; Otter, S.J.; Stewart, A.J. Adaptive Radiotherapy in the Management of Cervical Cancer: Review of Strategies and Clinical Implementation. Clin. Oncol. (R. Coll. Radiol.) 2021, 33, 579-590. [CrossRef]

40. Tod, M.C.; Meredith, W.J. A dosage system for use in the treatment of cancer of the uterine cervix. Br. J. Radiol. 1938, 11, 809-824. [CrossRef]

41. Tod, M.; Meredith, W. Treatment of cancer of the cervix uteri-A revised “Manchester method". Br. J. Radiol. 1953, 26, $252-257$. [CrossRef]

42. Haie-Meder, C.; Pötter, R.; Van Limbergen, E.; Briot, E.; De Brabandere, M.; Dimopoulos, J.; Dumas, I.; Hellebust, T.P.; Kirisits, C.; Lang, S. Recommendations from Gynaecological (GYN) GEC-ESTRO Working Group(I): Concepts and terms in 3D image based 3D treatment planning in cervix cancer brachytherapy with emphasis on MRI assessment of GTV and CTV. Radiother. Oncol. 2005, 74, 235-245. [CrossRef]

43. Pötter, R.; Haie-Meder, C.; Van Limbergen, E.; Barillot, I.; De Brabandere, M.; Dimopoulos, J.; Dumas, I.; Erickson, B.; Lang, S.; Nulens, A. Recommendations from gynaecological (GYN) GEC ESTRO working group (II): Concepts and terms in 3D imagebased treatment planning in cervix cancer brachytherapy-3D dose volume parameters and aspects of 3D image-based anatomy, radiation physics, radiobiology. Radiother. Oncol. 2006, 78, 67-77. [CrossRef]

44. Hellebust, T.P.; Kirisits, C.; Berger, D.; Pérez-Calatayud, J.; De Brabandere, M.; De Leeuw, A.; Dumas, I.; Hudej, R.; Lowe, G.; Wills, R. Recommendations from Gynaecological (GYN) GEC-ESTRO Working Group: Considerations and pitfalls in commissioning and applicator reconstruction in 3D image-based treatment planning of cervix cancer brachytherapy. Radiother. Oncol. 2010, 96, 153-160. [CrossRef]

45. Viswanathan, A.N.; Erickson, B.; Gaffney, D.K.; Beriwal, S.; Bhatia, S.K.; Burnett, O.L., III; D'Souza, D.P.; Patil, N.; Haddock, M.G.; Jhingran, A. Comparison and consensus guidelines for delineation of clinical target volume for CT-and MR-based brachytherapy in locally advanced cervical cancer. Int. J. Radiat. Oncol. Biol. Phys. 2014, 90, 320-328. [CrossRef] [PubMed]

46. Image Guided Intensity Modulated External Beam Radiochemotherapy and MRI Based Adaptive Brachytherapy in Locally Advanced Cervical Cancer (EMBRACE-II) Study Protocol v.1.0. Rumpold. 2016. Available online: https://www.embracestudy. dk/UserUpload/PublicDocuments/EMBRACE\%20II\%20Protocol.pdf (accessed on 19 October 2021).

47. Dimopoulos, J.C.; Kirisits, C.; Petric, P.; Georg, P.; Lang, S.; Berger, D.; Pötter, R. The Vienna applicator for combined intracavitary and interstitial brachytherapy of cervical cancer: Clinical feasibility and preliminary results. Int. J. Radiat. Oncol. Biol. Phys. 2006, 66, 83-90. [CrossRef] [PubMed]

48. Tanderup, K.; Nielsen, S.K.; Nyvang, G.-B.; Pedersen, E.M.; Røhl, L.; Aagaard, T.; Fokdal, L.; Lindegaard, J.C. From point A to the sculpted pear: MR image guidance significantly improves tumour dose and sparing of organs at risk in brachytherapy of cervical cancer. Radiother. Oncol. 2010, 94, 173-180. [CrossRef] [PubMed]

49. Fokdal, L.; Sturdza, A.; Mazeron, R.; Haie-Meder, C.; Tan, L.T.; Gillham, C.; Segedin, B.; Jurgenliemk-Schultz, I.; Kirisits, C.; Hoskin, P.; et al. Image guided adaptive brachytherapy with combined intracavitary and interstitial technique improves the therapeutic ratio in locally advanced cervical cancer: Analysis from the retroEMBRACE study. Radiother. Oncol. 2016, 120, 434-440. [CrossRef]

50. Serban, M.; Kirisits, C.; de Leeuw, A.; Pötter, R.; Jürgenliemk-Schulz, I.; Nesvacil, N.; Swamidas, J.; Hudej, R.; Lowe, G.; Hellebust, T.P. Ring versus ovoids and intracavitary versus intracavitary-interstitial applicators in cervical cancer brachytherapy: Results from the EMBRACE I study. Int. J. Radiat. Oncol. Biol. Phys. 2020, 106, 1052-1062. [CrossRef]

51. Charra-Brunaud, C.; Harter, V.; Delannes, M.; Haie-Meder, C.; Quetin, P.; Kerr, C.; Castelain, B.; Thomas, L.; Peiffert, D. Impact of 3D image-based PDR brachytherapy on outcome of patients treated for cervix carcinoma in France: Results of the French STIC prospective study. Radiother. Oncol. 2012, 103, 305-313. [CrossRef]

52. Sturdza, A.; Potter, R.; Fokdal, L.U.; Haie-Meder, C.; Tan, L.T.; Mazeron, R.; Petric, P.; Segedin, B.; Jurgenliemk-Schulz, I.M.; Nomden, C.; et al. Image guided brachytherapy in locally advanced cervical cancer: Improved pelvic control and survival in RetroEMBRACE, a multicenter cohort study. Radiother. Oncol. 2016, 120, 428-433. [CrossRef]

53. Potter, R.; Tanderup, K.; Schmid, M.P.; Jurgenliemk-Schulz, I.; Haie-Meder, C.; Fokdal, L.U.; Sturdza, A.E.; Hoskin, P.; Mahantshetty, U.; Segedin, B.; et al. MRI-guided adaptive brachytherapy in locally advanced cervical cancer (EMBRACEI): A multicentre prospective cohort study. Lancet Oncol. 2021, 22, 538-547. [CrossRef] 
54. Jensen, N.B.K.; Pötter, R.; Kirchheiner, K.; Fokdal, L.; Lindegaard, J.C.; Kirisits, C.; Mazeron, R.; Mahantshetty, U.; Jürgenliemk-Schulz, I.M.; Segedin, B. Bowel morbidity following radiochemotherapy and image-guided adaptive brachytherapy for cervical cancer: Physician-and patient reported outcome from the EMBRACE study. Radiother. Oncol. 2018, 127, 431-439. [CrossRef]

55. Fokdal, L.; Pötter, R.; Kirchheiner, K.; Lindegaard, J.C.; Jensen, N.B.K.; Kirisits, C.; Chargari, C.; Mahantshetty, U.; Jürgenliemk-Schulz, I.M.; Segedin, B. Physician assessed and patient reported urinary morbidity after radio-chemotherapy and image guided adaptive brachytherapy for locally advanced cervical cancer. Radiother. Oncol. 2018, 127, 423-430. [CrossRef]

56. Kim, Y.J.; Kang, H.C.; Kim, Y.S. Impact of intracavitary brachytherapy technique (2D versus 3D) on outcomes of cervical cancer: A systematic review and meta-analysis. Strahlenther Onkol. 2020, 196, 973-982. [CrossRef] [PubMed]

57. Kim, H.; Rajagopalan, M.S.; Beriwal, S.; Huq, M.S.; Smith, K.J. Cost-effectiveness analysis of 3D image-guided brachytherapy compared with 2D brachytherapy in the treatment of locally advanced cervical cancer. Brachytherapy 2015, 14, 29-36. [CrossRef] [PubMed]

58. Gill, B.S.; Lin, J.F.; Krivak, T.C.; Sukumvanich, P.; Laskey, R.A.; Ross, M.S.; Lesnock, J.L.; Beriwal, S. National Cancer Data Base analysis of radiation therapy consolidation modality for cervical cancer: The impact of new technological advancements. Int. J. Radiat. Oncol. Biol. Phys. 2014, 90, 1083-1090. [CrossRef] [PubMed]

59. O'Donnell, B.; Shiao, J.C.; Pezzi, T.A.; Waheed, N.; Sharma, S.; Bonnen, M.D.; Ludwig, M.S. Stereotactic Body Radiation Therapy, Intensity-Modulated Radiation Therapy, and Brachytherapy Boost Modalities in Invasive Cervical Cancer: A Study of the National Cancer Data Base. Int. J. Gynecol. Cancer 2018, 28, 563-574. [CrossRef] [PubMed]

60. Albuquerque, K.; Tumati, V.; Lea, J.; Ahn, C.; Richardson, D.; Miller, D.; Timmerman, R. A Phase II Trial of Stereotactic Ablative Radiation Therapy as a Boost for Locally Advanced Cervical Cancer. Int. J. Radiat. Oncol. Biol. Phys. 2020, 106, 464-471. [CrossRef] [PubMed]

61. Cheng, H.Y.; Liang, J.A.; Hung, Y.C.; Yeh, L.S.; Chang, W.C.; Lin, W.C.; Chen, S.W. Stereotactic body radiotherapy for pelvic boost in gynecological cancer patients with local recurrence or unsuitable for intracavitary brachytherapy. Taiwan J. Obs. Gynecol. 2021, 60, 111-118. [CrossRef]

62. Yegya-Raman, N.; Cao, C.D.; Hathout, L.; Girda, E.; Richard, S.D.; Rosenblum, N.G.; Taunk, N.K.; Jabbour, S.K. Stereotactic body radiation therapy for oligometastatic gynecologic malignancies: A systematic review. Gynecol. Oncol. 2020, 159, 573-580. [CrossRef]

63. Alexandrov, L.B.; Nik-Zainal, S.; Wedge, D.C.; Aparicio, S.A.; Behjati, S.; Biankin, A.V.; Bignell, G.R.; Bolli, N.; Borg, A.; Børresen-Dale, A.-L. Signatures of mutational processes in human cancer. Nature 2013, 500, 415-421. [CrossRef]

64. Wang, J.; Li, Z.; Gao, A.; Wen, Q.; Sun, Y. The prognostic landscape of tumor-infiltrating immune cells in cervical cancer. Biomed. Pharmacother. 2019, 120, 109444. [CrossRef]

65. The Cancer Genome Atlas Research Network; Albert Einstein College of Medicine; Analytical Biological Service; Barretos Cancer Hospital; Baylor College of Medicine; Beckman Research Institute of City of Hope; Buck Institute for Research on Aging; Canada's Michael Smith Genom e Sciences Centre; Harvard Medical School; Helen, F. Graham Cancer Centre and Research Institute at Christiana Care Health Services; et al. Integrated genomic and molecular characterization of cervical cancer. Nature 2017, 543, 378-384.

66. Liu, C.; Lu, J.; Tian, H.; Du, W.; Zhao, L.; Feng, J.; Yuan, D.; Li, Z. Increased expression of PD-L1 by the human papillomavirus 16 E7 oncoprotein inhibits anticancer immunity. Mol. Med. Rep. 2017, 15, 1063-1070. [CrossRef] [PubMed]

67. Mezache, L.; Paniccia, B.; Nyinawabera, A.; Nuovo, G.J. Enhanced expression of PD L1 in cervical intraepithelial neoplasia and cervical cancers. Mod. Pathol. 2015, 28, 1594-1602. [CrossRef] [PubMed]

68. Frenel, J.S.; Le Tourneau, C.; O’Neil, B.; Ott, P.A.; Piha-Paul, S.A.; Gomez-Roca, C.; van Brummelen, E.M.J.; Rugo, H.S.; Thomas, S.; Saraf, S.; et al. Safety and Efficacy of Pembrolizumab in Advanced, Programmed Death Ligand 1-Positive Cervical Cancer: Results From the Phase Ib KEYNOTE-028 Trial. J. Clin. Oncol. 2017, 35, 4035-4041. [CrossRef] [PubMed]

69. Chung, H.C.; Ros, W.; Delord, J.P.; Perets, R.; Italiano, A.; Shapira-Frommer, R.; Manzuk, L.; Piha-Paul, S.A.; Xu, L.; Zeigenfuss, S.; et al. Efficacy and Safety of Pembrolizumab in Previously Treated Advanced Cervical Cancer: Results from the Phase II KEYNOTE-158 Study. J. Clin. Oncol. 2019, 37, 1470-1478. [CrossRef] [PubMed]

70. Naumann, R.W.; Hollebecque, A.; Meyer, T.; Devlin, M.-J.; Oaknin, A.; Kerger, J.; López-Picazo, J.M.; Machiels, J.-P.; Delord, J.-P.; Evans, T.R.J.; et al. Safety and Efficacy of Nivolumab Monotherapy in Recurrent or Metastatic Cervical, Vaginal, or Vulvar Carcinoma: Results from the Phase I/II CheckMate 358 Trial. J. Clin. Oncol. 2019, 37, 2825-2834. [CrossRef]

71. Colombo, N.; Dubot, C.; Lorusso, D.; Caceres, M.V.; Hasegawa, K.; Shapira-Frommer, R.; Tewari, K.S.; Salman, P.; Hoyos Usta, E.; Yañez, E.; et al. Pembrolizumab for Persistent, Recurrent, or Metastatic Cervical Cancer. N. Engl. J. Med. 2021, 385, $1856-1867$. [CrossRef]

72. Lorusso, D.; Colombo, N.; Coleman, R.L.; Randall, L.M.; Duska, L.R.; Xiang, Y.; Hasegawa, K.; Rodrigues, A.N.; Cibula, D.; Mirza, M.R.; et al. ENGOT-cx11/KEYNOTE-A18: A phase III, randomized, double-blind study of pembrolizumab with chemoradiotherapy in patients with high-risk locally advanced cervical cancer. J. Clin. Oncol. 2020, 38, TPS6096. [CrossRef] 